\title{
ХАРАКТЕРИСТИКИ ИЗЛУЧЕНИЯ ОДНОЗЕРКАЛЬНЫХ АНТЕНН, ЧАСТИЧНО ПОКРЫТЫХ СЛОЕМ ВОДЫ
}

\author{
СУХАРЕВСКИЙ О. И. ${ }^{1}$, НЕЧИТАЙЛО С. В. ${ }^{1}$, ВОЙТОВИЧ О. А. ${ }^{2}$, ХЛОПОВ Г. И. ${ }^{2}$ \\ ${ }^{1}$ Харьковский университет Воздушных Сил, \\ Украина, Харьков, 61023, ул. Сумская 77/79 \\ ${ }^{2}$ Институт радиофизики и электроники Национальной Академии наук Украины, \\ Украина, Харьков, 61085, ул. Проскуры 12
}

\begin{abstract}
Аннотация. Проведен анализ влияния пленки воды на поверхности зеркала на характеристики излучения однозеркальных антенн. Рассчитаны коэффициент усиления и диаграмма направленности однозеркальных антенн различной геометрии с использованием метода физической оптики и решения модельной задачи о рассеянии плоской электромагнитной волны на диэлектрическом слое, расположенном на идеально проводящей подложке. Проведены измерения характеристик излучения однозеркальных антенн в 3 см диапазоне длин волн и сравнение полученных результатов с расчетными данными. Показано, что предложенный метод расчета обеспечивает хорошее соответствие экспериментальных и теоретических данных
\end{abstract}

Ключевые слова: однозеркальная антенна; осадки; диаграмма направленности; коэффициент усиления антенны

\section{ВВЕДЕНИЕ}

В настоящее время однозеркальные антенны $[1,2]$ широко используются в составе различных радиотехнических систем. Появление в процессе эксплуатации на поверхности зеркала слоя осадков (вода, снег, лед и др.) приводит к искажению диаграммы направленности (ДН) и уменьшению коэффициента усиления (КУ) антенны. Поэтому при проектировании антенных устройств для радиотехнических систем, подверженных воздействию внешних условий, необходимо учитывать влияние осадков на параметры антенн.

Цель настоящей работы - теоретическое и экспериментальное исследование влияния слоя жидких осадков (вода или растаявший снег) на поверхности зеркала на характеристики излучения однозеркальных параболических антенн.

\section{1. ПОСТАНОВКА ЗАДАЧИ}

Пусть зеркало антенны представляет собой круговую вырезку из параболоида вращения (рис. 1), в фокусе которого $(z=f)$ расположен облучатель. Будем рассматривать остронаправленные антенны, для которых выполняется условие: $2 a>\lambda$, где $\lambda$ - рабочая длина волны.

В общем случае зеркало антенны может быть ориентировано наклонно, а направление главного максимума ДН отклонено от вертикали на некоторый угол $\alpha$, в связи с чем слой осадков располагается несимметрично относительно оптической оси зеркала (рис. 2).

При этом предполагается, что в центре зеркала, как правило, имеется отверстие для удаления воды, благодаря чему вода в параболическом зеркале накапливается до достижения краев зеркала или стекает в отверстие в 